[3] Dooley MA, Jayne D, Ginzler EM, Isenberg D, Olsen NJ, Wofsy D, et al. Mycophenolate versus azathioprine as maintenance therapy for lupus nephritis. The New England journal of medicine 2011;365(2011):18861895.

Acknowledgements: None

Disclosure of Interest: None declared

DOI: 10.1136/annrheumdis-2018-eular.6609

\section{AB0531 DECISION TO INITIATE IMMUNOSUPPRESSION IN PATIENTS WITH PRIMARY SJOGREN'S SYNDROME}

S. Daia-lliescu, C. Buzatu, T. Gudu, D. Zaharia, C. Purice, A. Borangiu, I. Saulescu, L. Groseanu, C. Constantinescu, M.M. Negru, V. Vlad, V. Bojinca, F. Berghea, A. Balanescu, D. Predeteanu, R. Ionescu, D. Opris-Belinski. Internal Medicine and Rheumatology, SF. Maria Clinical Hospital, Carol Davila University of Medicine and Pharmacy, Bucharest, Romania

Background: There is limited data available (case series, small clinical trials and expert opinion) regarding the need to initiate immunosuppressive therapy in patients with primary Sjogren syndrome (pSS).

Objectives: The aim of this study is to determine the factors that correlate with physician's decision to start immunosuppressive therapy in pSS patients.

Methods: Subjects with pSS diagnosed according to the classification criteria in use at the time of their first presentation, were included in a monocentric cohort. A retrospective analysis was performed. The EULAR Sjogren's Syndrome Disease Activity Index (ESSDAI) at onset and Sjogren Syndrome Damage Index(SSDI) at the last evaluation were calculated. Treatment was given according to the physician's decision. Laboratory tests and Ultrasonography(US) of major salivary glands were performed in all cases. The data was analysed using Windows Excel/ SPSS20.0.

Results: Corticotherapy was prescribed in $26 / 30$ cases (86.6\%), mean duration 50.65 months. Immunomodulatory treatment with hydroxychloroquine was given in $26 / 30$ cases $(86.6 \%)$. Immunosuppressive treatment was required in $10 / 30$ patients (33.3\%)- azathioprine $7(23.3 \%)$ cases, methotrexate $3(10 \%)$ cases.

The mean ESSDAI score was 6.83 \pm SD 1.8. In 19 (63.3\%)cases disease activity was moderate or high (ESSDAI >5). The mean damage score value (SSDI) was 3.1 \pm SD1.2. There was a moderate correlation between the activity score ESSDAI and the damage score SDDI $(r=0.41, p<0,05)$. The physician's decision to start immunosuppression corelated significantly with the presence of hypergammaglobulinemia $(r=0.4, p<0,05)$. The duration of immunosuppressive treatment corelated moderately with specific Sjogren's US pattern of salivary glands ( $r=0.40$, $\mathrm{p}<0.05)$. In contrast, immunosuppressive treatment duration did not corelate with the activity and damage scores (ESSDAI and SSDI).

Conclusions: An important number of patients received corticotherapy, immunomodulatory agents and immunosuppressive therapy. The decision to initiate and maintain immunosuppressive therapy correlated with hypergammaglobulinemia and specific Sjogren's US changes. The damage score(SSDI) does not correlate with immunosuppressive therapy duration.

\section{REFERENCES:}

[1] Rischmueller M, Tieu J, Lester S. Primary Sjögren's syndrome. Best Pract Res Clin Rheumatol 2016 Feb 30.

[2] Seror R, Bootsma H, Saraux A, et al. Defining disease activity states and clinically meaningful improvement in primary Sjögren's syndrome with EULAR primary Sjögren's syndrome disease activity (ESSDAI) and patient-reported indexes (ESSPRI). Ann Rheum Dis 2016.

Disclosure of Interest: None declared

DOI: 10.1136/annrheumdis-2018-eular.4992

\section{$\mathrm{AB} 0532$ \\ THE EFFECTIVENESS OF EXERCISE THERAPY IN PATIENTS WITH SYSTEMIC SCLEROSIS: A SYSTEMATIC REVIEW}

S.I.E. Liem ${ }^{1}$, T.P.M. Vliet-Vlieland ${ }^{2}$, J.W. Schoones ${ }^{3}$, J.K. de Vries-Bouwstra ${ }^{1}$. ${ }^{1}$ Rheumatology; ${ }^{2}$ Orthopeadics; ${ }^{3}$ Walaeus Medical Library, Leiden University Medical Centre, Leiden, Netherlands

Background: Exercise therapy is an important and relatively often used nonpharmacological intervention ${ }^{1}$, yet its effectiveness based on studies where exercise therapy is evaluated as single intervention (and not part of a comprehensive program $^{2}$ ) has not been determined.

Objectives: To evaluate the effectiveness of exercise therapy in SSc patients by means of a systematic review of the literature.
Methods: A systematic literature search was performed in February 2017 in ten databases including Pubmed and Embase from 1990 to February 2017. We included clinical studies with an observational or experimental design as long as the study population concerned $>3$ SSc patients, the intervention consisted only of exercise therapy (categorised into hand exercises, mouth opening exercises and aerobic exercises either or not combined with other exercises) and its clinica outcome according to at least one assessment of effectiveness done before and after the intervention was reported. Studies where exercise therapy was part of a multidisciplinary intervention were excluded. The selection of studies, data extraction and assessment of methodological quality was done by two of the researchers independently.

Results: The search strategy yielded 636 titles and abstracts, with eventually six studies being included (2 randomised controlled trials (RCTs), 3 observationa designs (ODs) and 1 single subject experimental design (SSED)). The total num ber of patients included per study ranged from 4 to 48 , patients' mean age from 44.0 to 66.5 years and mean disease duration from 3.5 to 12.6 years. One study concerned hand exercises (an RCT comparing strengthening and mobility exercises using a telemedicine intervention consisting of a portable device guiding patients during workout and sending data to health professionals to no-telemedicine), two studies on mouth stretching and oral-augmentation exercises (an OD and a RCT), and three studies on aerobic exercise (two ODs and one SSED; one program with only aerobic training and two programs combining aerobic and resistance training, lasting 30-60 min, 2-3 days/week for 8-12 weeks). The study on hand exercises reported a greater improvement of hand function using the telemedicine intervention. The RCT on mouth exercises showed a statistically significant effect on maximum mouth opening in the exercise group compared to no exercise at 3 months but not at 6 months follow-up, whereas the OD showed improvement of mouth opening directly after the mouth exercise program. The three studies on aerobic exercise indicate effectiveness and no dropouts were observed. The program of solely aerobic exercise on a treadmill improved patient's exercise tolerance and aerobic capacity. The two programs combining aerobic and resistance exercise showed improvements of strength and muscle function in the OD and improvements of muscular endurance and aerobic capacity in the SSED.

Conclusions: The literature on the effect of exercise therapy in SSc patients is scanty. Collaborative efforts to conduct methodologically sound intervention studies with adequate reporting is needed. ${ }^{3}$

\section{REFERENCES}

[1] Meijs J, et al. Clin Rheumatol 2013;33(6):825-832.

[2] Willems L, et al. Arthritis Care \& Res. 2015;67(10):1426-1439.

[3] Ravaud P, et al. Nat Clin Pract Rheumatol 2006;2(6):313-319.

Disclosure of Interest: None declared

DOI: 10.1136/annrheumdis-2018-eular.7037

\section{AB0533 1 PATTERN OF DRUG USE IN SYSTEMIC LUPUS ERYTHEMATOSUS IN REAL WORLD CLINICAL PRACTICE}

T. Costa ${ }^{1}$, M. Eusébio ${ }^{2}$, S. Falcão ${ }^{1}$, F. Araújo ${ }^{3}$, P. Nero ${ }^{4}$, L. Inês ${ }^{5}$, M. Rodrigues ${ }^{5}$, D. Jesus ${ }^{5}$, S. Barreira ${ }^{6}$, C. Macieira ${ }^{6}$, M. Cabral $^{7}$, G. Sequeira $^{8}$, J. Branco $^{1}$, M. Santos ${ }^{9} .{ }^{1}$ Hospital Egas Moniz; ${ }^{2}$ Sociedade Portuguesa Reumatologia; ${ }^{3}$ Hospital Sant'Ana; ${ }^{4}$ Hospital CUF Descobertas, Lisboa; ${ }^{5}$ Centro Hospitalar Universitário, Coimbra; ${ }^{6}$ Centro Hospitalar Lisboa Norte, Hospital de Santa Maria, Centro Académico de Medicina, Lisboa; ${ }^{7}$ Hospital Fernando Fonseca, Amadora; ${ }^{8}$ Centro Hospitalar Universitário do Algarve, Faro; ${ }^{9}$ Hospital Garcia de Orta, Almada, Portugal

Background: Pharmacological treatment for systemic lupus erythematosus (SLE) is aimed at reducing disease activity, preventing flares and minimising the damage. The use of medication varies widely and therapeutic strategies are well defined only for certain organ manifestations. Hydroxychloroquine is the standard treatment for most SLE patients during the entire disease course, while immunosuppressants are recommended for those with severe organ involvement. Belimumab is the only biological currently licensed for SLE, although others are used offlabel in clinical practice.

Objectives: To describe the real-world patterns of drug use in SLE patients, and their relationship with disease phenotype.

Methods: Observational study of adult SLE patients registered in the Rheumatic Diseases Portuguese Registry, who have clinical diagnosis of SLE, followed for at least 1 year and with available data on medication, which was retrieved. Sociodemographic and clinical characteristics were compared among treatment groups defined as: group 1 antimalarials and/or glucocorticoids; group 2 immunosuppres sants (azathioprine (AZA)/mycophenolate mofetil (MM)/methotrexate (MTX) tantimalarials and/or glucocorticoids; group 3 biologics \pm immunosuppressants and/or antimalarials and/or glucocorticoids. To assess possible differences 